the factors causing stress; the requirements for particular jobs, how stress and fatigue in them can be reduced and assessed; the selection of the worker for a particular job and his supervision. The chemical environment is evaluated in a contribution by Dr. John A. Zapp, Jr.

The book is of value in that it presents an aspect of industrial work which has in the past received little consideration, while its well-documented factual content will provide more than an interesting introduction to some of the problems of human engineering with which the physician, the manager, and the engineer in industry should be acquainted.

\section{P. Priban}

Occupational First Aid, 2nd ed. (Pp. 73; illustrated. 4s. 6d.) London: The St. John Ambulance Association. 1961 .

The second and improved edition of Occupational First Aid published by the St. John Ambulance Association has now made its appearance.

It is more profusely illustrated although the two-colour illustrations are rather lurid and might be clearer in black and white.

In accordance with current practice the Association has recognized that first aiders in industry do perform treatment for minor injuries and illnesses without medical supervision, and it has devoted almost one-third of the book to this subject.

There are two points of criticism. Both sterility and no-touch dressing techniques are difficult subjects to teach to first aiders, and it appears unwise to the reviewer to show a dressing trolley set up with mixed sterile and non-sterile objects on the same shelf. It is an accepted principle that the upper shelf should contain sterile objects only and that such non-sterile requisites as bandages and the cetrimide bottle should be confined to the lower shelf.

The other point concerns haemorrhage. There is no mention of elevation of the limb and of lying the patient down before proceeding to the final and dangerous step of applying a rubber constrictive bandage. There are many people who believe that this appliance should be banished from the armamentarium of the first aider.

Despite these criticisms this edition will be read widely by first aiders in industry and should also be studied by managers who have the responsibility for providing first aid services in their factories-especially if they are not guided by the advice of a doctor trained in industrial medicine.

\section{R. A. TREVETHICK}

A Survey of Some Current Surgical Dressing Techniques. Report of an Occupational Health Section Scholarship Project (Studies in Nursing No. 2). By M. Margaret Williams. (Pp. 76; 6 figures. 6s. 6d.) London: The Royal College of Nursing. 1961.

The Royal College of Nursing has published a survey of surgical dressing techniques carried out in the medical departments of a cross-section of industry in this country. It is a report which should be read and digested by all doctors and nurses who perform or are responsible for treatment in industry, and it should serve as a yardstick against which their own techniques can be measured.

Some 35 suspected dangerous practices are discussed, which should form the basis for any heart searching and reorganization of technique. All these faults appear to have been transgressed by some of the respondents, for example, Suspected Dangerous Practice number 35, and perhaps one of the most important, is concerned with the segregation of clean and dirty cases. The cubicle system in the treatment room is probably one of the most effective ways of doing this.

After making comment on all the 35 suspected dangerous practices, a graph is shown in which the sepsis rate, calculated from the cases at risk and the number going septic, is plotted against the number of transgressions of ideal technique. It appears that a higher rate of sepsis exists in those medical departments that commit the greatest number of suspected dangerous practices, and also, as an interesting sideline, it is brought out that heavy industry is more liable to have a high sepsis rate than light industry.

The reviewer would take issue on one point which concerns the definition of sepsis, "the slightest inflammation indicates some degree of sepsis". If this were taken as the criterion for sepsis then almost $100 \%$ of lacerations and burns would be classed as septic since they heal by a process of inflammatory repair. Surely sepsis should be defined as a condition where there is heat, redness, swelling, throbbing pain, lymphangitis, and discharge of pus. Any combination of these signs indicates that the normal process of repair has been superseded by added infection.

This criticism apart, the survey is most helpful in pinpointing pitfalls into which it is too easy to slip. One of the most telling phrases used is the very last one in the book, "all practice should be under constant review". It is surprising to find that there are departments where daily dressings still take place. In the survey it is recommended that dressings should be undisturbed for 24 hours in the first place and then should be looked at every three days. It is even more desirable to the reviewer's mind that the dressing should remain undisturbed for a minimum of five days and on occasions 10 days, and this is quite possible in industry if patients are instructed how to wash and avoid getting their dressings wet. Top bandages can always be replaced if dirty.

Much is made of the use of standard packs ready sterilized for finger and other dressings. Disposable gallipots of aluminium foil and paper towels are all excellent ways of eliminating cross-infection.

This survey deserves a wide distribution, and if its advice is followed there should be a drastic reduction in cross-infection of casualties treated in industry.

\section{R. A. Trevethick}

Tidy's Massage and Remedial Exercises in Medical and Surgical Conditions, 10th ed. Edited and revised by J. O. Wale. (Pp. viii $+600 ; 192$ figures. 42s.) Bristol: John Wright. 1961. 
This well-known book of Miss Tidy's, which is intended for senior students and recently qualified physiotherapists, has been revised by Mrs. J. O. Wale, formerly physiotherapist in charge of the neurological section of St. Thomas's Hospital.

In contradistinction to its title, it describes not only physical treatment but also the anatomy, the pathology, and the medical and surgical treatment of almost every condition likely to be encountered by a physiotherapist.

The book outlines in detail all injuries and diseases of the skeletal and locomotor systems, and the section on neurological conditions is excellent. General medical conditions, classwork, and the problems of treating children and the aged are dealt with adequately.

The general layout of the book with small typescript gives the impression of crowding and is difficult to read even though frequently broken up by sub-headings. As pointed out by the editor, controversy has been avoided. This is perhaps inevitable in a textbook of this nature, but because of it the book is rather dry reading.

In spite of these criticisms this is a very useful book with a good reference system and it would be an asset to any physiotherapist's library.

\section{J. R. BURrows}

L'Elettroencefalogramma in Medicina del Lavoro. By Carlo Serra and Luigi Ambrosio. (Pp. 320; 101 figures. L.6.000.) Naples: Acta Neurologica. 1961.

Carlo Serra and Luigi Ambrosio have written a most useful book on their studies of electroencephalograms made both in animal and human experiments. They wished, in particular, to study the effects of certain industrial poisons and hazards on the tracings.

In their first chapters they describe the effects of metabolic imbalance, of noise, and of overbreathing on the normal E.E.G. Later they deal with the effects of alcoholic excess, including accidental poisoning in industries using this material. Some of the effects of arsenic, of the halogens, of cyanide, mercury, and manganese are of great interest.

Poisoning with carbon monoxide provides interesting material for study, and the effects of cerebral lesions from this cause, illustrated by enlargements of microscope sections, may be correlated to some extent with the E.E.G. changes observed. Indeed, in certain cases of suspected poisoning of industrial origin, it may be only with E.E.G. evidence that one can assess the full extent of any damage suffered.

Clearly some of the changes are reversible, but if a subject has once clinically suffered effects from any poison, it may be found that further effects can be detected more easily, as in the case of carbon bisulphide poisoning described here, if this aid to diagnosis is available.

In recent years many new insecticides have been brought into use and, as is now better appreciated, some of them are extremely poisonous. A case of DDT poisoning is noted in which the electrical activity was slowed and a previously dominant frequency could no longer be seen. There were paroxysmal changes during hyperventilation deriving from the temporo-central area.
Eight months later this zone was still somewhat abnormal in its excitability.

Methyl bromide was found to be widespread in its effects on the brain and with no special point of attack.

Noxious physical agents were also studied, both mechanical injury and the effects of electric shock. Even after recovery from the immediate effects the E.E.G. may give useful information about residual damage which may be difficult or impossible to detect by the usual clinical methods.

Similar considerations apply to head injury of physical origin, and in some cases the apparent development of diabetes after accident, perhaps used as a basis for a compensation claim, may be better assessed with the help of E.E.G. evidence.

This book is illustrated with many excellent figures and diagrams.

\section{G. C. Pether}

Toxicity of Beryllium Compounds. By Lloyd B. Tepper, Harriet L. Hardy, and Richard I. Chamberlin. (Pp. viii +190 ; 10 figures +12 tables. 20s.) Amsterdam: Elsevier; London: Van Nostrand. 1961.

In 1949 beryllium ceased to be included in the phosphors which coat the inside of fluorescent lamp tubes. This year, in 1962, Imperial Chemical Industries announce the closure of their one-and-a-half million pound beryllium plant, since the metal has been found to be too brittle when it cools from relatively high temperatures to make satisfactory fuel cans for the Advanced Gas-cooled Reactor. The first of these decisions turned upon a point of health, the second upon metallurgy. Both of them represent two fundamental steps in the prevention of beryllium disease.

The toxicity of this metal and its compounds is fully described in this Elsevier Monograph which comes by General Hospital out of Institute of Technology, both from the world famous stable of Massachusetts. Here is seen the best kind of co-operation between two doctors and an industrial hygiene engineer, members of the staff of the Department of Medicine and of the local Occupational Medical Service.

The monograph, which will fit easily into the pocket, describes the terminology, history, epidemiology, and the acute and chronic forms of beryllium disease. The $x$-ray changes, pathology, and pulmonary function are then discussed. The final chapters deal with the beryllium patch test, the experimental toxicology, the route of the metal in the body, and the industrial hygiene aspects. There is a list of 297 references and an index.

A few positive, but at the same time tentative, suggestions for making the style go more easily to the reader may perhaps be made.

This pocket book is packed with information, broken up into a slightly staccato style by the continuous interjection of quoted references, together with many case studies. A continuous narrative, with grouped references under headings at the end of each chapter, might be smoother, combined perhaps with a simple summary of what has gone before. 